\title{
Exposing the Sea Floor: High-Resolution Multibeam Mapping Along the U.S. Pacific Coast
}

hat w ould you see if you
could drain the oceans and
take aerial photographs of the
sea floor? You w ould see views
like those produced by the U.S.
Geological Survey (USGS) using
high-resolution multibeam map-
ping systems. The USGS is map-
ping the sea floor off populated
areas, such as Southern
California and the Haw aiian
Islands, and under coastal and
inland w ater bodies, such as San
Francisco B ay and Lake Tahoe.
The resulting new images sup-
port studies of biological habi-
tats, offshore earthquake and
landslide hazards, waste dispos-
al, movement of sediment and
pollutants, and other coastal and
marine issues.

On July 29, 1865, the steamship Brother Jonathan was wrecked on an uncharted rock pinnacle near Crescent City, California. All but 19 of the 244 people aboard were killed, a tragedy that might have been averted had the captain known the rock was there. For as long as humans have ventured onto the sea, knowledge of the ocean bottom has been essential to their safety and success.

Today, nautical charts made by the National Oceanic and Atmospheric Administration (NOAA) help mariners recognize and avoid navigational hazards. A variety of sea-floor base maps, constructed by the U.S. Geological Survey (USGS) and other research groups, help scientists identify more far-reaching hazards- such as offshore earthquake faults, unstable undersea slopes, and pathways for the movement of sediment and pollutants.

Base maps are fundamental tools for studying not just offshore hazards but also

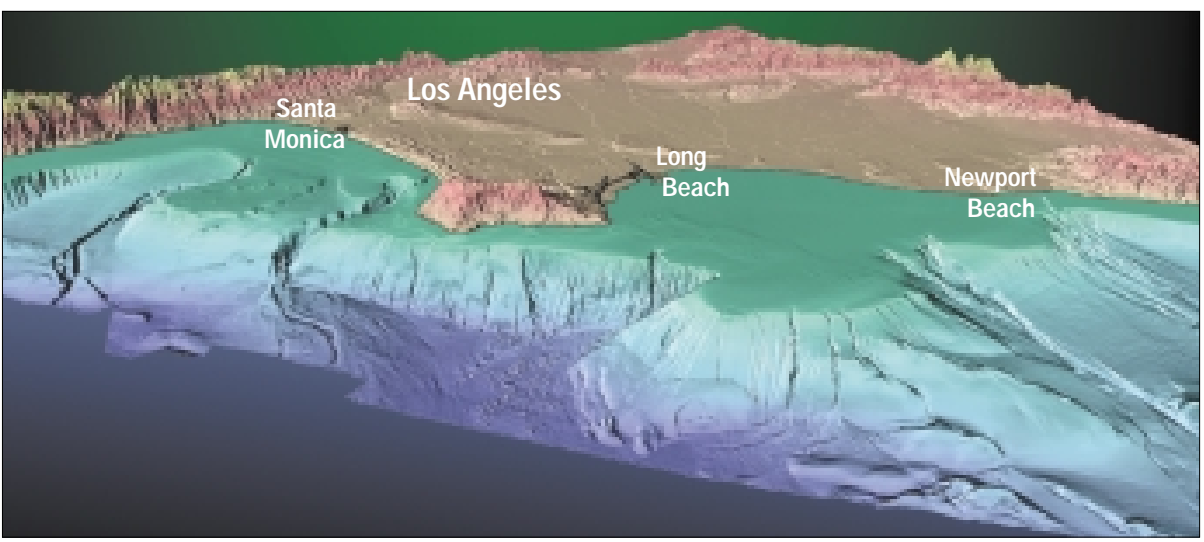

Sea floor off the Los Angeles area. Sea floor is in shades of blue and green. The Palos Verdes Peninsula is in the center of the coastline, Santa M onica Bay to the left, and San Pedro Bay to the right. From Santa Monica to New port Beach is about 65 kilometers ( 40 miles) as the crow flies. Slopes look steeper than they really are; vertical exaggeration is 20 to 1. (Image constructed from data collected in 1996, 1998, and 1999.)

natural resources and the offshore environment. They provide a context for recording and interpreting scientific data. For example, when scientists pull a sample of rock or sediment from the sea floor, they want to know: where is it from? is it from the bottom of a channel, from a small hill, or from a flat plain? The answers to such simple questions, which are necessary to help scientists understand the processes that shape the sea floor, are provided by accurate base maps.

Sea-floor base maps made over the past century range widely in accuracy. Older navigation systems resulted in features being mapped many meters or even kilometers from their actual geographic locations. Systems used to measure the distance to the sea floor resulted in water depths that might be off a few meters or tens of meters. Depending on the spatial resolution of the mapping system, objects below a certain size—such as shipwrecks or even undersea mountains - might not appear at all.

Methods of sea-floor mapping have improved over time (see back page). By the mid-1990's a new generation of sea-floor mapping systems, called high-resolution multibeam systems, had been developed. These systems send a fan of sound energy toward the sea floor and receive reflected sound through multiple narrow beams, each pointed at a different angle. They produce sea-floor maps of unprecedented accuracy. On the continental shelf (the extension of the continent below sea level), these systems can detect features as small as 1 meter across, and locate them to within 1 meter of their true geographic location and less than 50 centimeters of their true depth below sea level. The new systems not only provide bathymetric (depth) data, but also record the amount of sound energy returned to the mapping system from the sea floor, termed "backscatter." Backscatter data can help scientists identify the materials that make up the sea floor, such as rock, sand, or mud.

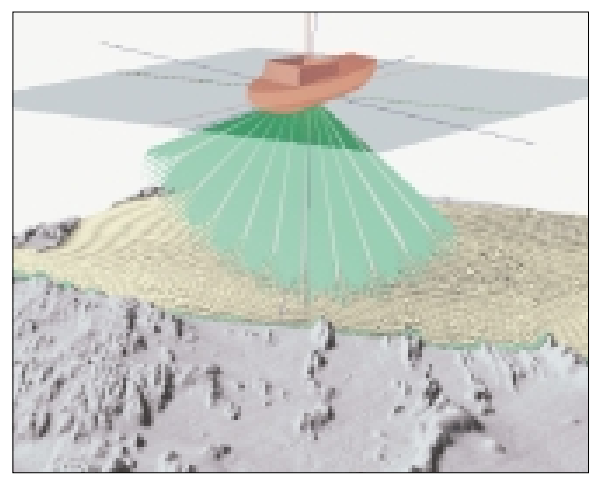

A hull-mounted high-resolution multibeam mapping system sends sound energy toward the sea floor and receives reflected sound through multiple narrow beams. As the ship moves forward (toward lower left), it maps a swath of sea floor. 


\section{Some Multibeam Mapping Images Produced by the USGS}

\section{To see more images, visit http://w alrus.w r.usgs.gov/pacmaps/}

\section{Floor of Central San Francisco Bay}

This image shows the floor of central San Francisco Bay-the deep part of the bay, where ocean-going vessels traverse the shipping lanes and strong tidal currents sculpt the bay floor. Collected in late 1996 and early 1997, the multibeam data used to produce this image provide a first look at such a large area of the bay floor in such detail.

Because multibeam data are digital, they can be manipulated in many ways. In this image, shadows have been added as if the sun were shining from the west. The resulting "shaded relief" makes details of the bayfloor topography easier to see and interpret.

The new bay-floor data can help answer some important questions:

- How do currents move sediment on the bay floor?

- Where can sediment dredged from harbors and shipping channels be most safely disposed of?

- What types of bay floor provide habitats for fish and shellfish?

- How much rock must be trimmed from pinnacles on the bay floor to ensure that big ships do not run aground on them? (See "Rock Pinnacles in San Francisco Bay," below.)

On-land portions of this image (tinted green) were created from topographic data, so the image shows no roads, buildings, or vegetation. Light blue areas are parts of San Francisco Bay and adjacent waters that were not mapped during this study.

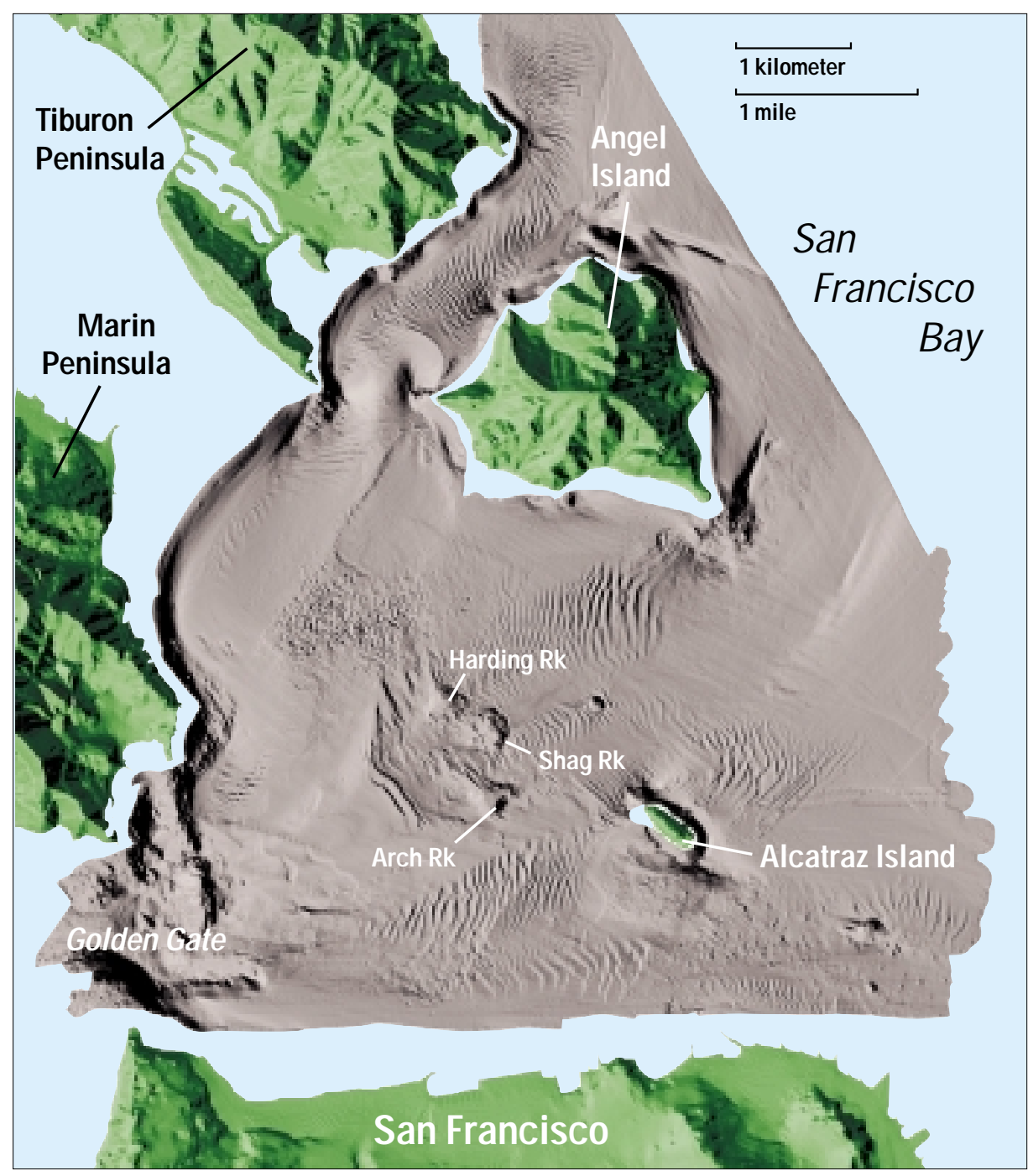

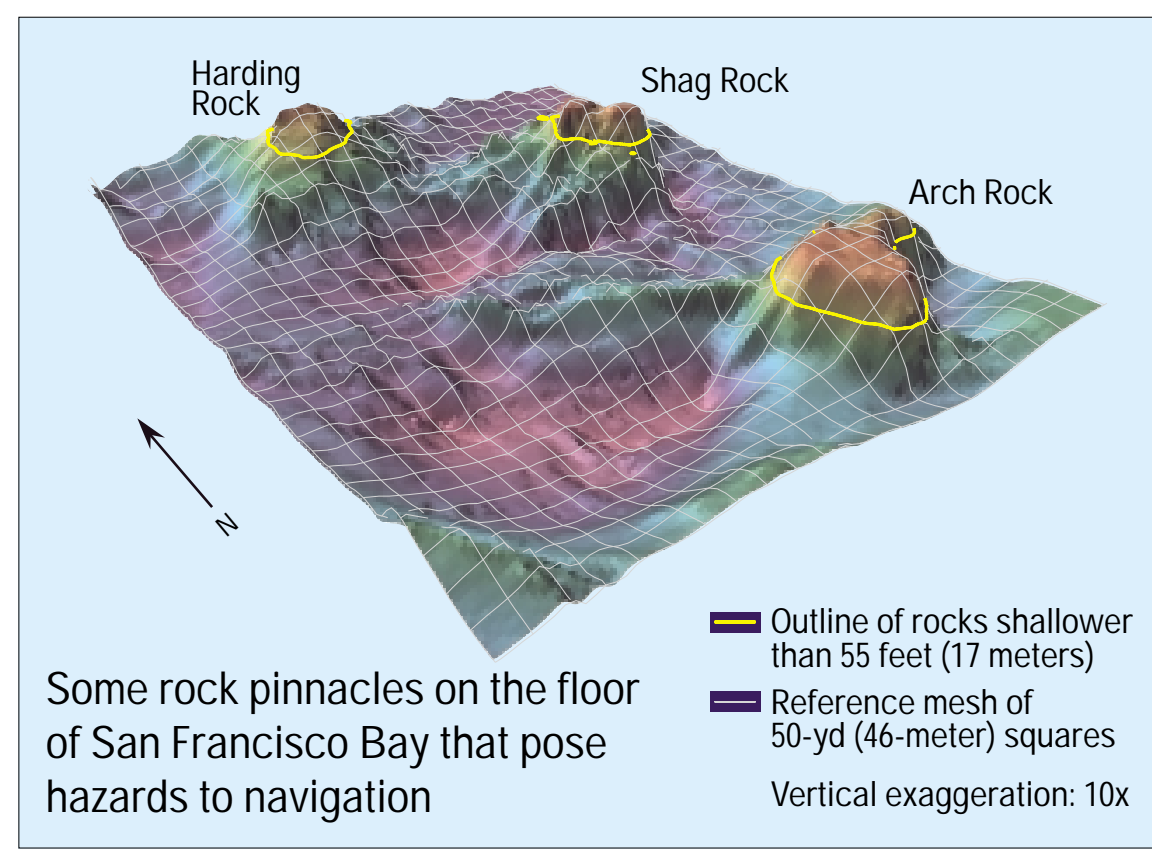

\section{Rock Pinnacles in San Francisco Bay}

On the shaded-relief image above, you can see three rock pinnacles rising from the floor of San Francisco Bay northwest of Alcatraz Island. They are shown in an oblique view at left, made from the same data used to make the shaded-relief image. Now under study is a plan to lower these and other rock pinnacles in the bay to promote safe ship travel and to prevent oil spills that might occur if a ship struck one of these rocks.

The detailed bathymetric data collected during multibeam mapping allowed the USGS to estimate the amount of rock that would have to be removed to lower these pinnacles to a safe depth for deepdraft vessels. From Harding Rock, for example, about 38,000 cubic meters of rock would have to be removed. This information is important for agencies planning to remove and dispose of the material.

(For more information, see USGS Open-File Report 98-139, http://sfbay.wr.usgs.gov/access/mapping/multibeam/) 

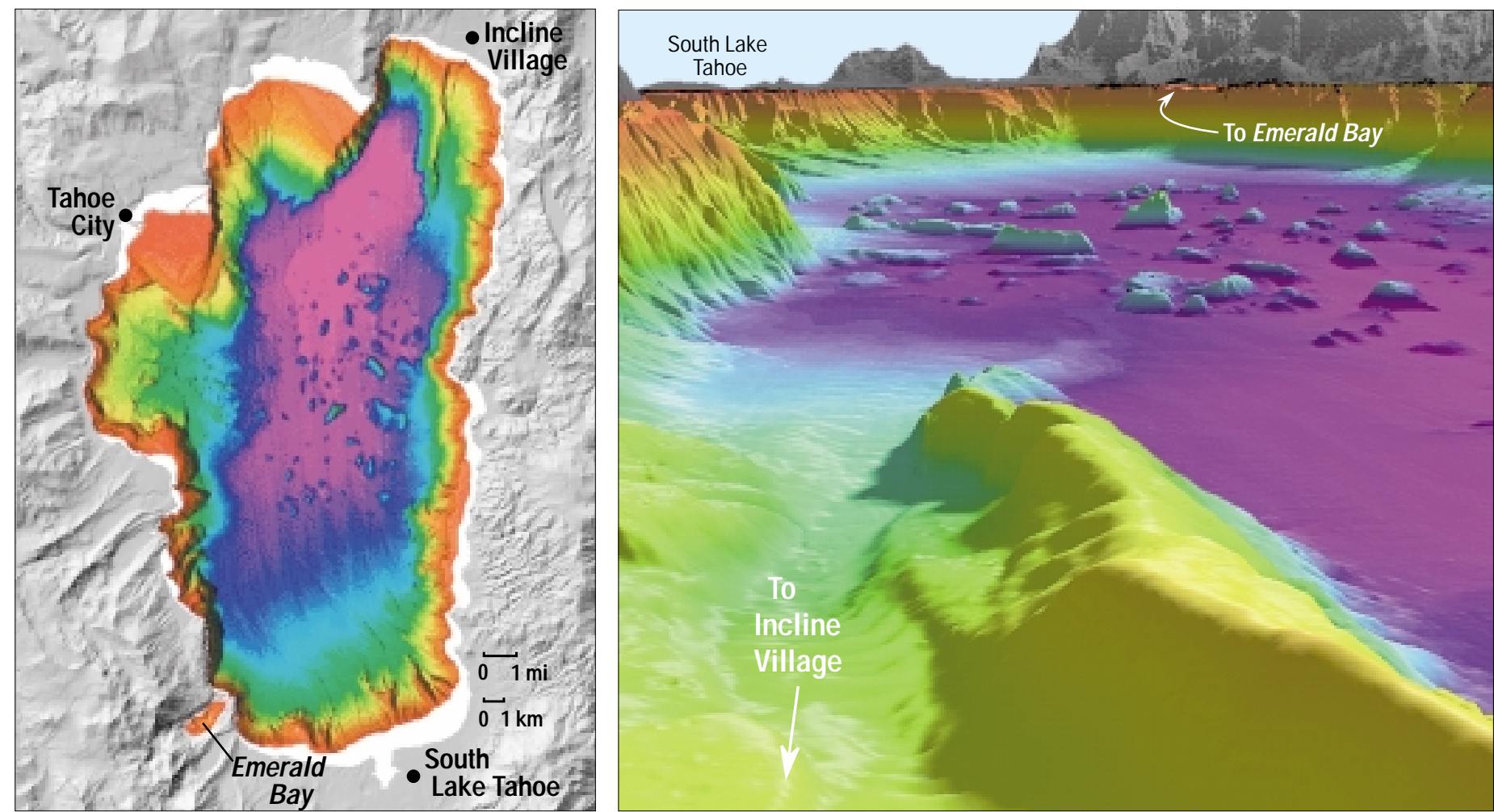

\section{B ottom of Lake Tahoe}

The USGS mapped the bottom of Lake Tahoe on the California-Nevada border in summer of 1998 - the first time since it had been roughly mapped in 1923. The mapping was undertaken in response to a 1997 Presidential Executive Order calling for cooperation between Federal agencies and other groups conducting research in the Lake Tahoe basin. The new base map will help all researchers in the basin conduct and coordinate their studies.

The pair of images above shows how the digital data can be presented in map view (on left) or in oblique views (on right). This oblique view looks south-southwest from near Incline Village toward the south shore of the lake (vertical exaggeration is 3 to 1 ).

(For more information, images, and a computer-generated fly-through movie, see http://blt.wr.usgs.gov/.)

\section{Mamala Bay, off Honolulu, Haw aii}

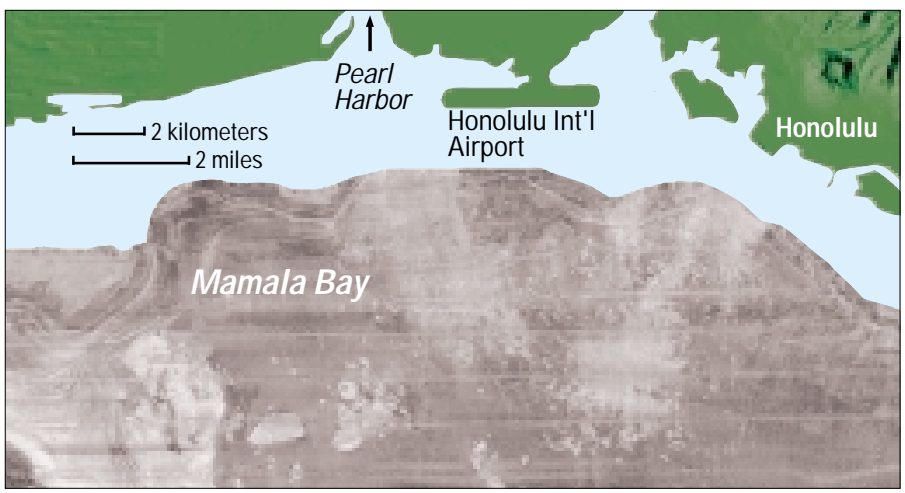

In 1998, the USGS conducted multibeam mapping off several of the Hawaiian Islands. This image shows backscatter data collected in Mamala Bay, south of Oahu. Backscatter is a measure of how much sound energy is reflected from the sea floor. Hard surfaces, such as rock and sand, reflect more sound energy than soft surfaces, such as mud. In this image, harder materials are bright, softer materials dark. Tiny, circular light patches in the middle of the bay floor are piles of material that was dredged from Pearl and Honolulu Harbors over the past century and dumped in Mamala Bay. The dumped material is resting on natural sediment.

This and other maps produced by the USGS will help the U.S. Army Corps of Engineers and the U.S. Environmental Protection Agency determine the volume and ultimate fate of materials disposed at sea-floor sites off the Hawaiian Islands.

\section{Sea Floor off San Diego}

The image below shows the sea floor off San Diego, California, which was mapped by the USGS in 1998. The undersea ridge labeled "Coronado Bank" is a sliver of continental crust shifted into its present position by movement along faults. Several of those faults run through Loma Sea Valley, between Coronado Bank and the narrow continental shelf off the San Diego area.

Eventually, USGS scientists plan to map the entire stretch of coast between the Mexican border (right edge of this image) and Santa Monica (just north of Los Angeles; see figure at top of first page). The slopes in this image look steeper than they really are; vertical exaggeration is 20 to 1 .

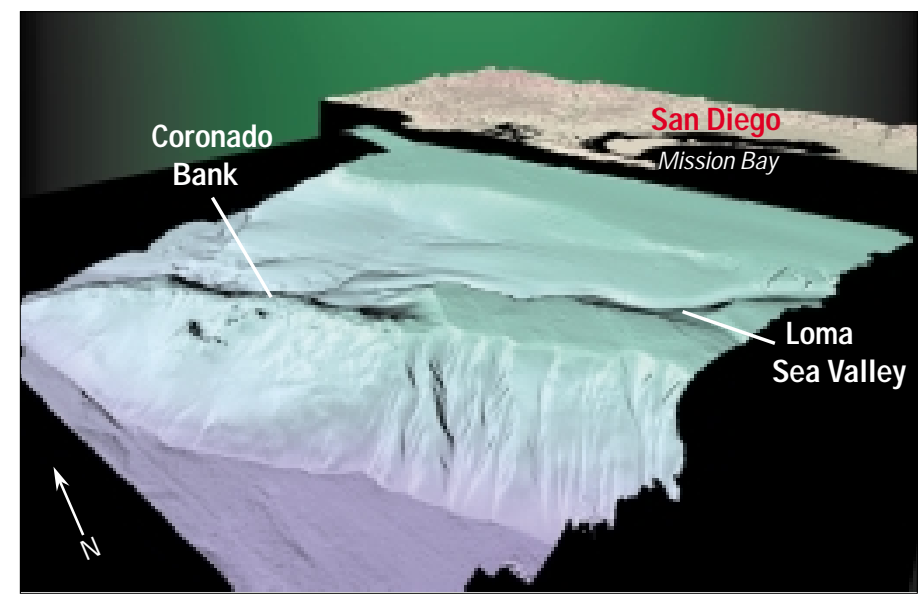




\section{A B rief History of Sea-Floor M apping}

Until the 20th century, seafarers used weighted lines to measure water depth. They assumed the distance to the sea floor was the same as the length of line that had to be let out before the weight hit bottom. They often recovered samples of sea-floor sediment as well, clinging to wax coatings on the weights or picked up by mechanical sampling devices.

These depth measurements, or soundings, were taken routinely only in rivers and coastal waters. Deep-ocean soundings were rare, took hours to perform, and could be wildly inaccurate. The weight of the line needed to measure great depths exceeded that of the end weight, making it difficult to tell when the weight hit bottom. Also, undersea currents and drift of the vessel caused the line to slant as it dropped toward the bottom, making the length of line let out greater than the vertical distance to the sea floor.

Today sound energy is used to measure distances in water. The modern term for this approach is "sonar" (SOund NAvigation and Ranging). Devices that use sound to measure distances in water were first invented in the early 20th century. They made it possible to measure water depths by a technique called "echo sounding."

In the simplest form of echo sounding, a pulse of sound sent from a ship travels to the sea floor and bounces back to a receiver on the ship. The time lapse between sending the sound pulse and receiving its echo is used to calculate water depth at that point.

In World War II, the U.S. Navy introduced continuous echo sounding, in which pulses of sound were sent at short intervals and the echoes converted into marks on a recording chart as a vessel was under way. The result was a continuous profile of the sea floor along the line that marked the ship's track.

In the 1950's, the Navy developed sidescan sonar to look for mines and other explosive devices. An instrument towed behind a ship sent out a fan of sound extending to either side of the ship's track.

Returning echoes produced an image of features along a swath of sea floor, the ship's track being in the center of the swath. By combining overlapping swaths of sidescansonar data, scientists produced the first photograph-like views of the sea floor.

Sidescan sonar also provides clues about what materials make up the sea floor. Hard materials such as rock and sand reflect more sound back to the sidescan receiver than soft materials such as mud. Scientists can study bright and dark areas in sidescan-

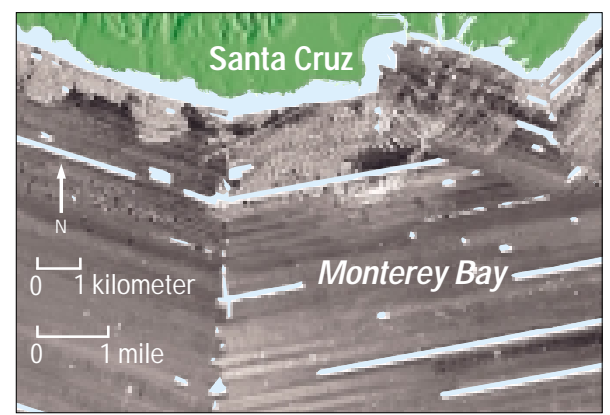

Image of sea floor off Santa Cruz, California, created from sidescan-sonar data collected in 1995 and 1996. Parallel bands in broad V-shape are swaths of sidescan-sonar data. Dark areas are muddy sediment. Bright areas are outcrops of bedrock and patches of sand. Light line angling southwestward from Santa Cruz is an outfall pipe.

sonar images and make inferences about what kinds of sea-floor materials have been imaged. Sea-floor samples are taken to confirm the scientists' interpretations.

Although sidescan sonar provides valuable views of the sea floor, it does not provide information on water depth. Also, researchers must make assumptions about the location of the towed sidescan device relative to the position of the ship, in order to determine the geographic location of areas depicted in sidescan-sonar images.

These problems are not present in the high-resolution multibeam swath-mapping systems developed in the 1990's. In these systems, a hull-mounted transducer sends out a fan of sound, then records sound reflected from the sea floor through a set of narrow receivers aimed at different angles. These systems collect bathymetric (waterdepth) data of such high resolution that they can distinguish depths that differ by just a few tens of centimeters (just a few centime-

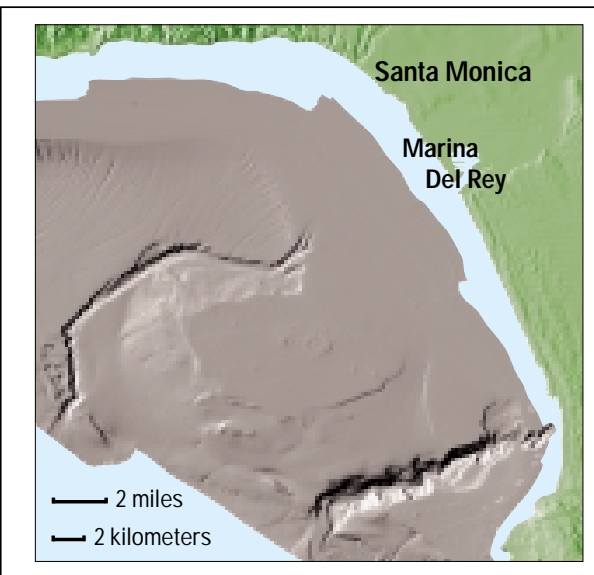

Two views of the floor of Santa M onica Bay created from high-resolution multibeam data (compare oblique view on front page). Left-hand image shows bathymetry, right-hand image shows backscatter. Brighter areas on backscatter image represent harder materials, probably rock and ters in shallow water). At the same time, the systems collect "backscatter" data, a measure of the amount of sound energy returned from the sea floor. Because the transducer is mounted on the ship's hull, both the bathymetric and the backscatter data are firmly tied to the ship's position, and compensations can be made for the ship's roll and other movements. Using differential GPS (Global Positioning System), high-resolution multibeam mapping can pinpoint sea-floor locations to within one meter. It can detect features as small as a meter across.

Multibeam mapping is part of the USGS Coastal and Marine Geology Program's ongoing efforts to provide information that will assist the careful management of our coasts and seas.

Authors: James V. Gardner, Peter Dartnell, Helen Gibbons, Duncan MacMillan

Contributors: Paul R. Carlson, Pat S. Chavez, Jr. John L. Chin, Stephen L. Eittreim, Deborah Lee Soltesz, Michael E. Torresan, Michael E. Field, Miguel Velasco, Florence L. Wong COOPERATING ORGANIZATIONS University of New Brunswick

U.S. Environmental Protection Agency U.S. Army Corps of Engineers U.S. Navy

$M$ inerals $M$ anagement Service

National Oceanic and Atmospheric Administration Orange County Sanitation District

Orange County Public Facilities and Resources Department Los Angeles County Sanitation District City of Long Beach Port of Long Beach

San Diego M etropolitan Waste Water Department M assachusetts Institute of Technology University of Hawaii Institute of M arine Biology
For more information contact:
U.S. Geological Survey, M S-999 345 M iddlefield Road Menlo Park, CA 94025 (650) 329-5042
http://walrus.w r.usgs.gov/

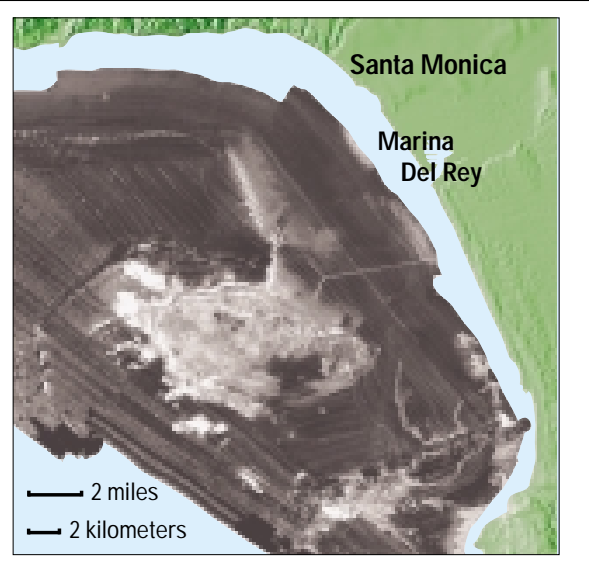

sand. Darker areas are softer materials, such as mud. Scientists are working to better understand the relationship between sea-floor materials and the backscatter images they produce, with the ultimate goal of using backscatter data to make maps of the materials on the sea floor. 